Supporting Table S2: Population genetic parameter estimates at the APL1A locus, considered separately for alleles falling in the $A P L 1 A^{1}$ and $A P L 1 A^{2}$ structural classes.

\begin{tabular}{|c|c|c|c|c|c|c|c|}
\hline Collection & $\mathrm{n}^{1}$ & $b p^{2}$ & $\pi_{\mathrm{tot}}^{3}$ & $\underline{\theta}_{\text {tot }}^{4}$ & $\mathrm{TajD}^{5}$ & $\pi_{\text {syn }}^{6}$ & $\pi_{\text {non }}{ }_{-}^{7}$ \\
\hline \multicolumn{8}{|l|}{$A P L 1 A^{1}$} \\
\hline Bancoumana dry & 19 & 1669 & 0.019 & 0.032 & -1.734 & 0.034 & 0.016 \\
\hline Bancoumana rainy & 9 & 1665 & 0.048 & 0.054 & -0.587 & 0.086 & 0.039 \\
\hline Toumani-Oulena & 6 & 1669 & 0.058 & 0.062 & -0.434 & 0.103 & 0.050 \\
\hline Makouchetoum & 4 & 1669 & 0.054 & 0.057 & -0.598 & 0.076 & 0.051 \\
\hline all pooled & 38 & 1665 & 0.048 & 0.048 & 0.623 & 0.104 & 0.106 \\
\hline
\end{tabular}

\title{
APL1A $^{2}$
}

Bancoumana dry $\quad 0$

Bancoumana rainy 0

$\begin{array}{llllllll}\text { Toumani-Oulena } & 4 & 1917 & 0.017 & 0.015 & 0.919 & 0.150 & 0.082\end{array}$

$\begin{array}{llllllll}\text { Makouchetoum } & 6 & 1872 & 0.023 & 0.024 & -0.457 & 0.034 & 0.018\end{array}$

$\begin{array}{llllllll}\text { all pooled } & 10 & 1872 & 0.021 & 0.023 & -0.542 & 0.034 & 0.016\end{array}$

${ }^{1}$ number of alleles sequenced, no $A P L 1 A^{2}$ alleles were found in the Bancoumana dry population ${ }^{2}$ locus size, in base pairs, excluding insertions and deletions

${ }^{3}$ average number of differences per pair of alleles, per nucleotide

${ }^{4}$ Watterson's estimator of the population genetic parameter $4 \mathrm{~N}_{\mathrm{e}} \mathrm{m}$

${ }^{5}$ Tajima's $D$ test statistic

${ }^{6}$ average number of difference per pair of alleles, per nucleotide, synonymous sites only

${ }^{7}$ average number of difference per pair of alleles, per nucleotide, nonsynonymous sites only 